\title{
Histidine Production by Corynebacterium glutamicum Mutants, Multiresistant to Analogs of Histidine, Tryptophan, Purine and Pyrimidine ${ }^{\dagger}$
}

\author{
Kazumi Araki, Setsuko Shrmojo and Kiyoshi Nakayama \\ Tokyo Research Laboratory, Kyowa Hakko Kogyo Co., Ltd., Machida-shi, Tokyo \\ Received November 15, 1973
}

\begin{abstract}
The histidine productivity of 1,2,4-triazole-3-alanine (TRA)-resistant histidine producer, Corynebacterium glutamicum $\mathrm{KY}-10260$ was improved by successive additions of such markers as purine, pyrimidine, histidine and tryptophan analog-resistance to the mutant. A selected mutant AT-83, multi-resistant to 6-mercaptoguanine, 8-azaguanine, 4-thiouracil, 6-methylpurine, TRA and 5-methyltryptophan, accumulated twice as much histidine as KY-10260 in the culture medium. The level of histidine production by this mutant reached $15 \mathrm{mg} / \mathrm{ml}$ or $10 \%(\mathrm{w} / \mathrm{w})$ of the initial suagr in the medium containing $6 \%$ (as glucose concentration) cane molasses and $9 \%$ sucrose as carbon sources. 2-Fluoroadenine-resistant mutants produced adenine in addition to histidine.
\end{abstract}

At present, the involvement of 5-phosphoribosylpyrophosphate (PRPP) in the biosynthesis of histidine has well been known. ${ }^{3 \sim 8 \text { ? }}$ The first step of histidine biosynthesis is a condensation of adenosine $5^{\prime}$-triphosphate (ATP) and PRPP. The biosynthetic pathway leading to ATP involves the purine pathway. PRPP also serves as a skeleton upon which the heterocyclic ring of purine is built.

The biosynthesis of PRPP in Salmonella typhimurium $^{9,10}$ and Escherichia coliti,12) is inhibited by adenosine $5^{\prime}$-diphosphate (ADP) and less effectively by other purine nucleotides, pyrimidine nucleotides and tryptophan at the step of PRPP synthetase (EC 2.7.6.1). The formation of PRPP synthetase of S. typhimurium has recently been revealed to be repressed by uridine nucleotides. ${ }^{13,14)}$ The adenine nucleotide synthesis in bacterial systems is also regulated by purine derivatives. PRPP amidotransferase (EC 2.4.2.14), the first enzyme of the purine pathway, from Aerobacter aerogenes $^{15)}$ is inhibited by guanosine $5^{\prime}$-monophosphate (GMP), adenosine $5^{\prime}$-monophosphate (AMP) and guanosine 5 -triphosphate (GTP), and less effectively by ADP and inosine

$\dagger$ Studies on Histidine Fermentation. Part III. For previous papers, Part I and Part II, see Ref. 1) and 2). $5^{\prime}$-monophosphate (IMP). In Bacillus subtilis, ${ }^{16)}$ the enzyme inhibition by guanine nucleotides is much less than that of the adenine nucleotides, and IMP has been shown to be ineffective. The inhibitory effect of 5 -aminoimidazole 4carboxamide ribonucleotide (AICAR) and of ATP on this enzyme is also described in $S$. typhimurium $^{5}$ and Brevibacterium ammoniagenes, ${ }^{37}$ respectively. Adenylosuccinate synthetase (EC 6.3.4.4), the first enzyme in the AMP-specific pathway, is inhibited by guanosine 5'-diphosphate (GDP) and GMP, and less effectively by AMP and ADP in E. coli. ${ }^{17)}$ The GDP inhibition is much less than that of AMP and ADP in B. subtilis. ${ }^{18)}$ Formation of the enzymes of the common pathway for the purine nucleotide synthesis is repressed by the derivatives of both adenine and guanine or by either of them, in S. typhimurium, ${ }^{19)} A$. aerogenes, ${ }^{19,20)}$ E. coli, ${ }^{5)}$ B. subtilis ${ }^{21,29)}$ and $B$. ammoniagenes. ${ }^{37}$ The formation of the adenylosuccinate synthetase is repressed by adenine derivatives in $B$. subtilis ${ }^{22,23)}$ and in A. aerogenes. ${ }^{203}$

As has been described in our previous report, ${ }^{1)}$ histidine analog-resistant mutants of Corynebacterium glutamicum accumulated 6 $7 \mathrm{mg} / \mathrm{ml}[4 \sim 4.7 \%(\mathrm{w} / \mathrm{w})$ of the initial sugar $]$ of 
histidine in the culture medium, and the high production of histidine by these mutants was explained in terms of the lack of end product regulation on the histidine pathway. If, in these mutants, the histidine pathway is so extensively relieved of the end product regulation that the biosynthesis of such precursors of histidine as PRPP and adenine nucleotides limits the histidine production, the increase of the biosynthesis of the precursors will lead an increased production of histidine. Moreover, it has generally been recognized in bacterial systems that the mutations causing resistance to a structural analog of a normal metabolite involves a mutation causing overproduction of the metabolite or its related metabolites.

Based on these facts, we attempted the improvement of histidine productivity of a histidine-producing mutant, $C$. glutamicum $\mathrm{KY}-10260$, by letting it be resistant successively to each analog of purine, pyrimidine, histidine and tryptophan.

\section{MATERIALS AND METHODS}

Microorganisms. Corynebacterium glutamicum KY-10260, a histidine producer which had previously ${ }^{13}$ been derived as TRA-resistant from a wild-type strain ATCC 13761 was used as the original parent strain of all the analog-resistant mutants described in this paper.

Mutagenesis. Every mutagenesis was performed by the treatment of bacterial cells with N-methyl-N'nitro-N-nitrosoguanidine (NTG). Prior to the mutagenesis, the sensitivity of a parent strain to an analog was tested by streaking the cells on a minimal agar medium supplemented with the analog at various concentrations from 50 to $8000 \mu \mathrm{g} / \mathrm{ml}$ and incubating at $30^{\circ} \mathrm{C}$. The analog-resistant mutant was selected on the agar medium containing the analog at twice to ten times the minimal inhibitory concentration of the parent strain.

Culture method. Compositions of the media employed for histidine production-test were shown in the legend of each table and figure. Composition of the minimal medium was previously ${ }^{1 /}$ described. Fermentation was carried out in a $250-\mathrm{ml}$ Erlenmeyer flask for $92 \sim 96 \mathrm{hr}$ by the manner described in the previous paper. ${ }^{11}$

Analysis. Histidine and the growth of the microorganisms were estimated by the manner described in the preceding paper. ${ }^{2}$ Adenine was estimated spectrophotometrically from the absorbancy at $260 \mathrm{~nm}$ after paper-chromatographic separation and the elution with hot water.

Reagents. Sources of the reagents are as follows: 6-Mercaptoguanine and 8-azaguanine from Nutritional Biochemicals Co., 6-mercaptopurine, dithiouracil, 6-methylpurine and 5-methyltryptophan from Sigma Chemical Co., 4-thiouracil and 3-amino-1,2,4-triazole from Tokyo Kasei Kogyo Co., Ltd., 2-thiazolealanine and DL-1,2,4-triazole-3-alanine from Eli Lilly \& Co., and tubercidin from Calbiochem. 2-Fluoroadenine was synthesized by Mr. Teranishi of our laboratory according to the method of Montgomery. ${ }^{24)}$

\section{RESULTS}

1. Improvement by the addition of single purine analog-resistance

The biosynthetic pathways leading to adenine nucleotides and PRPP in bacterial systems are regulated by purine nucleotides. PRPP amidotransferase, the first enzyme of the purine pathway, has been shown to be subject to the feed back inhibition of AMP, ADP, ATP, GMP, GDP, IMP or AICAR in A aerogenes, ${ }^{15}$ ) $B$. subtilis, ${ }^{16,25)}$ S. typhimurium ${ }^{53}$ and $B$. ammoniagenes. ${ }^{37}$ Adenylosuccinate synthetase, the first enzyme for the conversion of IMP to AMP, is inhibited by AMP, ADP, GMP, GDP or their related nucleotides in $E$. coli ${ }^{17}$ and $B$. subtilis. ${ }^{18)}$ The formation of the enzymes for the adenine nucleotide synthesis is repressed by the derivatives of adenine and guanine, in $S$. typhimurium, $A$. aerogenes, $E$. coli, $B$. subtilis and $B$. ammoniagenes. ${ }^{5,19 \sim 23,37)}$ PRPP synthetase from $S$. typhimurium ${ }^{0,10}$ and $E$. coli ${ }^{11,12)}$ is inhibited by purine nucleotides. ADP is the most effective inhibitor in both cases.

Furthermore, such purine analogs as 6-mercaptopurine (MP), 6-mercaptoguanine (MG) and 8-azaguanine (AG) are shown to mimic some of the above-described regulatory action of the normal metabolites after conversion to the nucleotide corresponding to each analog. ${ }^{26,27)}$ Moreover, these analogs have been shown to inhibit the growth of a $C$. glutamicum strain. ${ }^{28}$ 2-Fluoroadenine (FA) has been shown to be a feed back inhibitor of 
Table I. Histidine Production by Purine Analog-resistant Derivatives of C. glutamicum KY-10260

Fermentation medium: $15 \%$ (as glucose concentration) cane molasses, $4.5 \%\left(\mathrm{NH}_{4}\right)_{2} \mathrm{SO}_{4}, 0.15 \%$ $\mathrm{KH}_{2} \mathrm{PO}_{4}, 0.05 \% \mathrm{~K}_{2} \mathrm{HPO}_{4}, 0.05 \% \mathrm{MgSO}_{4} \cdot 7 \mathrm{H}_{2} \mathrm{O}, 0.3 \%$ urea, $3 \% \mathrm{CaCO}_{3} ; \mathrm{pH} 7.2$.

\begin{tabular}{|c|c|c|c|c|}
\hline \multirow[b]{2}{*}{ Class of mutants } & \multirow{2}{*}{$\begin{array}{l}\text { No. of } \\
\text { mutants } \\
\text { tested }\end{array}$} & \multicolumn{3}{|c|}{ Best histidine producer in each class } \\
\hline & & $\begin{array}{c}\text { Strain } \\
\text { No. }\end{array}$ & $\begin{array}{l}\text { Histidine } \\
\text { produced } \\
(\mathrm{mg} / \mathrm{ml})\end{array}$ & $\begin{array}{l}\text { Growth } \\
\text { (OD } 660 \\
\times 1 / 100)\end{array}$ \\
\hline \multicolumn{5}{|l|}{ Resistant to } \\
\hline 2-Fluoroadenine $(>1000 \mu \mathrm{g} / \mathrm{ml})$ & 73 & $\mathrm{FA}-43$ & 6.7 & 0.53 \\
\hline 6-Mercaptoguanine $(>1000 \mu \mathrm{g} / \mathrm{ml})$ & 80 & $\mathrm{MG}-15$ & 7.4 & 0.64 \\
\hline 6-Mercaptopurine $(>200 \mu \mathrm{g} / \mathrm{ml})$ & 50 & MP-22 & 5.5 & 0.64 \\
\hline 8-Azaguanine $(>500 \mu \mathrm{g} / \mathrm{ml})$ & 47 & $\mathrm{AG}-121$ & 7.0 & 0.76 \\
\hline (Parent) & & $K Y-10260$ & 5.2 & 0.62 \\
\hline
\end{tabular}

purine biosynthesis in $E$. coli. ${ }^{29}$

Based on these informations, we expected that some mutation causing $C$. glutamicum resistance to these analogs would allow the overproduction of precursors of histidine, PRPP and ATP, and the overproduction of them would result in an increased production of histidine in a histidine producer. At first, we attempted the derivation of the mutants resistant to these analogs from a TRA-resistant histidine producer, C. glutamicum KY-10260. Resistants were selected on the agar media containing one of these analogs at the concentration indicated in Table $\mathrm{I}$. The concentrations used were much higher than $62.5 \mu \mathrm{g} / \mathrm{ml}$, the level which completely inhibited the growth of the parent strain KY-10260 in a preliminary experiment. Two hundred and fifty mutants thus obtained were tested for histidine productivity in a medium containing $15 \%$ (as glucose concentration) cane molasses as carbon source. Table I shows the histidine production by four strains, each gave the highest yield of histidine in each class of the mutants selected on agar containing different analog. As can be seen, a MG-resistant mutant MG-15, an $A G-r e s i s t a n t$ mutant $A G-121$ and a FAresistant mutant FA-43 produced 7.4, 7.0 and $6.7 \mathrm{mg} / \mathrm{ml}$ of histidine, respectively. These values were higher than that $(5.2 \mathrm{mg} / \mathrm{ml})$ given by the parent strain $\mathrm{KY}-10260$. Out of them, strain $M G-15$ was selected as parent strain for the further mutation to improve the his- tidine productivity in the following experiment. The histidine productivity of the MP-resistant mutants was comparable with that of $\mathrm{KY}$ 10260 , but was lower than that of $M G-15$, AG-121 and FA-43.

\section{By-production of adenine by FA-resistant} derivatives of $K Y-10260$

In the experiment described above, it was found that all the FA-resistant derivatives of KY -10260 accumulated $0.5 \sim 2.0 \mathrm{mg} / \mathrm{ml}$ of adenine in addition to histidine in the culture medium. Identification as adenine was obtained from the agreement of its $R f$-values in paper-chromatography (Table II) and its UV-absorption spectrum with those of authentic adenine. In comparing the amount of adenine with that of histidine produced by each FA-resistant mutant, it was noted, as

TABLE II. PAPER-Chromatographic IDENTIFICATION WITH ADENINE, OF AN UV-ABSORBING SUBSTANCE

PRODUCED BY 2-FLUOROADENINE-RESISTANTS (Rf-values)

\begin{tabular}{ccc}
\hline $\begin{array}{c}\text { Solvent } \\
\text { system }\end{array}$ & $\begin{array}{c}\text { Substance } \\
\text { produced } \\
\text { by mutant }\end{array}$ & $\begin{array}{c}\text { Authentic } \\
\text { adenine }\end{array}$ \\
\hline A & 0.60 & 0.60 \\
B & 0.12 & 0.12 \\
C & 0.94 & 0.95 \\
\hline
\end{tabular}

a) Solvent system: A, $n$-propanol- $0.2 \mathrm{~N} \mathrm{NH}_{4} \mathrm{OH}$ (3: $) ; \mathrm{B}$, isopropanol- $\mathrm{CH}_{3} \mathrm{COONa}-\left(\mathrm{NH}_{4}\right)_{2} \mathrm{SO}_{4}-$ saturated solution $(2: 19: 79) ; \mathrm{C}$, isobutyric acid-1 $\mathrm{NH}_{4} \mathrm{OH}(5: 1)$. 
shown in Fig. 1, that low production of histidine tended to accompany high production of adenine and that high production of histidine did not always accompany low production of adenine. For example, FA-21, FA-60 and FA-69 which were three lowest histidine producers, gave the highest yield of adenine. Strain FA-43 which gave the highest yield of histidine accumulated $1.2 \mathrm{mg} / \mathrm{ml}$ of adenine, the amount of adenine being comparable with that $(1.2 \sim 1.3 \mathrm{mg} / \mathrm{ml})$ given by strain FA-18 or FA-45 which exhibited low histidine productivity. Adenine was also produced by FA-resistant derivatives of a wild-type strain C. glutamicum ATCC 13761, from which all the mutants described here were originated, as reported else where. ${ }^{30}$

\section{Improvement by the addition of double} purine analog-resistance

A MG-resistant mutant, MG-15 gave the highest yield of histidine in the previous experiment (Table I). The improvement of the histidine productivity of this mutant was attempted by a further addition of AGresistance marker to the mutant, because the emergence of AG-resistance in KY-10260 was rather effective on the histidine production

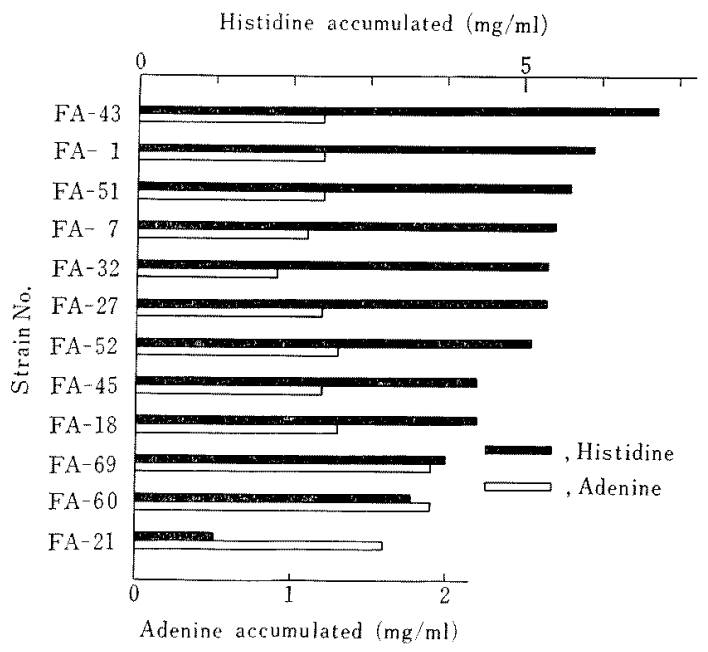

FIG. 1. Relation between the Histidine Titers and Adenine By-production by 2-Fluoroadenine-resistant Derivatives of a Histidine Producer, C. glutamicum KY-10260.
(Table I). As a result of a histidine production-test with 32 mutants of such MG- and AG-resistants, a mutant MGAG-16 gave the highest yield $(7.8 \mathrm{mg} / \mathrm{ml})$ of histidine. This mutant was used as the parent strain for the further mutation to improve the histidine productivity in the next experiment.

\section{Improvement by the addition of pyrimidine analog-resistance}

The biosynthesis of PRPP is inhibited by cytosine nucleotides and uridine nucleotides at the step of PRPP synthetase in S. typhimurium $^{9,10)}$ and E. coli. ${ }^{11,12}$ The formation of PRPP synthetase in S. typhimurium is repressed by uridine nucleotides. ${ }^{13,14)}$ The uridine nucleotides can be derived from uracil via "salvage pathway," and the cytosine nucleotides derive from the uridine nucleotides. ${ }^{3,311}$ Moreover, some pyrimidine-analogs cause the inhibition of bacterial growth by mimicing the regulatory effect of normal pyrimidine

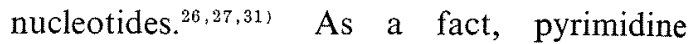
analogs, 4-thiouracil (4TU), 6-azauracil (6AU) and dithiouracil (DTU, 2,4-dithiopyrimidine) inhibited the growth of a histidine producer MGAG-16, which gave the highest yield of histidine in the preceding experiment, as well as wild-type strain C. glutamicum ATCC 13761, as shown in Table III.

Table III. Sensitivity of a Mutant MGAG-16 AND Its Parent Wild-TYPe StRaIn C. glutamicum

ATCC 13761 to Various Pyrimidine-ANalogs

\begin{tabular}{lcc}
\hline \multirow{2}{*}{$\begin{array}{c}\text { Pyrimidine- } \\
\text { analogs }\end{array}$} & \multicolumn{2}{c}{$\begin{array}{c}\text { Minimal inhibitory } \\
\text { concentration }(\mu \mathrm{g} / \mathrm{ml})^{a /}\end{array}$} \\
\cline { 2 - 3 } & MGAG-16 & ATCC 13761 \\
\hline 4-Thiouracil & 250 & 250 \\
6-Azauracil & 100 & 100 \\
Dithiouracil & 100 & 100 \\
\hline
\end{tabular}

a) Tested by streaking the culture onto a minimal agar medium containing the analog.

Based on these situations and the similar assumption as that described for the derivation of purine analog-resistant mutants, we expected a high production of histidine by the mutants resistant to these pyrimidine-analogs. Such 
Table IV. Distribution of Pyrimidine Analog-resistant Derivatives of MGAG-16 with Respect to Histidine Productivity

Fermentation medium: The same as that in Table $\mathrm{I}$ except that $0.75 \%$ meat extract was added.

\begin{tabular}{|c|c|c|c|c|c|c|c|}
\hline \multirow{2}{*}{$\begin{array}{l}\text { Class of } \\
\text { mutants }\end{array}$} & \multirow{2}{*}{$\begin{array}{l}\text { No. of } \\
\text { mutants } \\
\text { tested }\end{array}$} & \multicolumn{6}{|c|}{$\begin{array}{c}\text { No. of strains producing } \\
\text { histidine in amount }(\mathrm{mg} / \mathrm{ml}) \text { of }\end{array}$} \\
\hline & & $6>$ & $6 \sim 7$ & $7 \sim 8$ & $8 \sim 9$ & $9 \sim 10$ & $10 \sim 11$ \\
\hline \multicolumn{8}{|l|}{ Resistant $^{a}$ to } \\
\hline 6-Azauracil & 69 & 6 & 7 & 17 & 26 & 13 & 0 \\
\hline 4-Thiouracil & 28 & 1 & 4 & 5 & 11 & 4 & 3 \\
\hline Dithiouracil & 40 & 2 & 6 & 10 & 14 & 7 & 1 \\
\hline
\end{tabular}

a) Mutants were derived in the presence of the analog at $500 \mu \mathrm{g} / \mathrm{ml}$.

Table V. Histidine Production by Best Histidine Producer in Each Class of Pyrimidine Analog-resistant Derivatives of C. glutamicum MGAG-16

Details of the experiment were the same as those in Table IV.

\begin{tabular}{|c|c|c|c|}
\hline $\begin{array}{l}\text { Class of } \\
\text { mutants }\end{array}$ & $\begin{array}{l}\text { Strain } \\
\text { No. }\end{array}$ & $\begin{array}{c}\text { Histidine } \\
\text { produced } \\
(\mathrm{mg} / \mathrm{ml})\end{array}$ & $\begin{array}{l}\text { Growth } \\
\left(\mathrm{OD}_{660} \times 1 / 100\right)\end{array}$ \\
\hline \multicolumn{4}{|l|}{ Resistant to } \\
\hline 6-Azauracil & 6AU6-37 & 9.9 & 0.62 \\
\hline 4-Thiouracil & 4 TU6-2 & 10.3 & 0.53 \\
\hline Dithiouracil & DTU6-2 & 10.1 & 0.63 \\
\hline (Parent) & $M G A G-16$ & 6.3 & 0.59 \\
\hline
\end{tabular}

mutants were derived from the MGAG-16. A histidine production-test with 137 mutants in all of 6AU-resistant, 4TU-resistant and DTUresistant mutants revealed that more than half of these pyrimidine analog-resistant mutants produced histidine at the higher levels than $8 \mathrm{mg} / \mathrm{ml}$, as shown in Table IV. As can be seen in Table $\mathrm{V}$, a 6AU-resistant mutant 6AU6-37, a 4TU-resistant mutant 4TU6-2 and a DTU-resistant mutant DTU6-2 produced $9.9,10.3$ and $10.1 \mathrm{mg} / \mathrm{ml}$ of histidine, respectively. Among them, strain 4TU6-2 was employed as the parent strain for a further mutagenesis in the next experiment.

5. Improvement by the addition of 6-methylpurine-resistance and tubercidin-resistance

In the preceding experiment, a $4 \mathrm{TU}$-resistant 4TU6-2 exhibited a high productivity of histidine. For a further improvement of its histidine productivity, we sought some purineanalogs which were inhibitory to the mutant. A purine analog, 6-methylpurine (MEP) and a nucleoside antibiotic, tubercidin ( $\mathrm{Tu}$ ) were found to completely inhibit the mutant's growth at 250 and $4000 \mu \mathrm{g} / \mathrm{ml}$, respectively. Therefore, the mutants resistant to each of these analogs were derived from 4TU6-2. As shown in Table VI, the amount of histidine produced by these mutants was $10 \mathrm{mg} / \mathrm{ml}$ at best. This value was comparable with that given by the parent strain 4TU6-2 in the preceding experiment (Table V), though it was higher than that given by the parent strain in this experiment. Based on this result, a MEP-resistant mutant TUM-39 listed in Table VI was used as parent strain in a further mutagenesis in the next experiment.

\section{Improvement by increasing the resistance to $T R A$}

FA was an unique purine-analog in that the emergence of resistance to it in a histidine producer KY-10260 caused the by-production of adenine (Fig. 1). In this case, a high production of histidine still accompanied the production of a considerable amount of adenine. Consequently, if the adenine nucleotide is used 
Table VI. Histidine Production by 6-Methylpurine-resistant Derivatives and Tubercidin-Resistant Derivatives of $C$. glutamicum 4TU6-2

Fermentation medium used was the same as that in Table IV.

\begin{tabular}{ccccc}
\hline & No. of & & \multicolumn{2}{c}{ Best histidine producer in each class } \\
\cline { 3 - 5 } Class of mutants & $\begin{array}{c}\text { mutants } \\
\text { tested }\end{array}$ & $\begin{array}{c}\text { Strain } \\
\text { No. }\end{array}$ & $\begin{array}{c}\text { Histidine } \\
\text { produced } \\
(\mathrm{mg} / \mathrm{ml})\end{array}$ & $\begin{array}{c}\text { Growth } \\
(\text { OD } \\
\times 1 / 100\end{array}$ \\
\hline $\begin{array}{c}\text { Resistant to } \\
\text { 6-Methylpurine }(>2000 \mu \mathrm{g} / \mathrm{ml})\end{array}$ & 60 & TUM-39 & 10.0 & 0.52 \\
Tubercidin $(>8000 \mu \mathrm{g} / \mathrm{ml})$ & 50 & TUT-44 & 8.9 & 0.51 \\
(Parent) & & 4TU6-2 & 7.8 & 0.62 \\
\hline
\end{tabular}

for the biosynthesis of histidine without being excreted into the medium as adenine, the histidine production will increase. This was expected in the case of a FA-resistant mutant simultaneously carrying 4TU-resistance, if the latter resistance allowed the overproduction of PRPP and the excess of PRPP was used for the histidine biosynthesis coupling with ATP. These situations prompted us to the derivation of FA-resistant mutants from TUM-39 which had been derived from a $4 T U$-resistant mutant 4TU6-2 in the preceding experiment. A FAresistant derivative TUMF-20 thus obtained produced $11.4 \mathrm{mg} / \mathrm{ml}$ of histidine. This value was rather higher than that $(10.7 \mathrm{mg} / \mathrm{ml})$ given by the parent strain TUM-39. Eight out of thirty FA-resistant derivatives produced adenine as well as histidine. As shown in Fig. 2, high histidine producers by-produced smaller amount of adenine than low histidine producers.

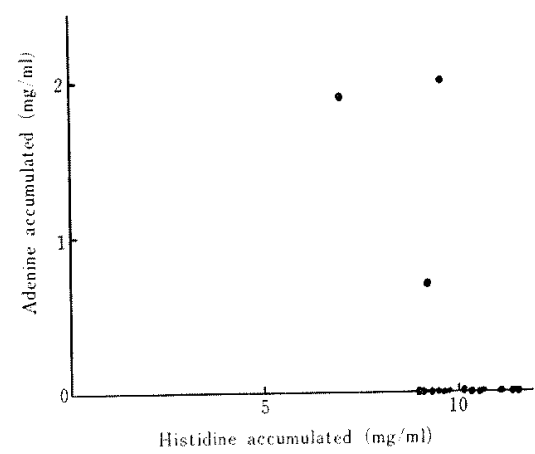

FIG. 2. Relation between Histidine Titers and Adenine By-production by 2-Fluoroadenine-resistant Derivatives of $C$. glutamicum TUM-39.
The growth of TUM-39 was delayed in the presence of such histidine-analogs ${ }^{4)}$ as 2thiazolealanine (TA), TRA or 3-amino-1,2,4triazole (AMT). Therefore, it seemed still possible in TUM-39 that histidine production is limited by the residual end product regulation on the histidine pathway. When $10^{7}$ NTGtreated cells of TUM-39 per plate were spread on a minimal agar medium supplemented with $200 \mu \mathrm{g} / \mathrm{ml}$ of TRA, 88 colonies appeared with a slight background growth on the entire agarsurface. When a similar experiment was performed with the medium supplemented with both of TA and AMT each at the concentration of $1000 \mu \mathrm{g} / \mathrm{ml}, 10$ colonies appeared with similar background growth. In the presence of either TA or AMT, only the slight growth over the entire agar-surface was observed, but no distinct colonies appeared. We isolated the colonies, which rapidly grew in the presence of these histidine-analogs, as the mutants highly resistant to the analogs. Two strains which gave the highest yield of histidine among the mutants, and the data on their histidine productivity are listed in Table VII. A mutant TUMT-24 selected from the mutants which grew rapidly in the presence of TRA produced a distinctly higher amount $(12.2 \mathrm{mg} / \mathrm{ml})$ of histidine than its parent strain $(10.7 \mathrm{mg} / \mathrm{ml})$.

\section{Effect of cane molasses-sucrose ratio on histidine production}

As reported in our previous papers, cane molasses contains some substance effective on the histidine production by a TRA-resistant histidine producer, $\mathrm{KY}-10260^{1)}$ and by its 
Table VII. Histidine Production by Histidine Analog-resistant Derivatrves of C. glutamicum TUM-39

The details of the experiment were the same as those in Table IV.

\begin{tabular}{ccccc}
\hline Class of mutants & $\begin{array}{c}\text { No. of } \\
\text { mutants } \\
\text { tested }\end{array}$ & $\begin{array}{c}\text { Strain } \\
\text { No. }\end{array}$ & $\begin{array}{c}\text { Histidine } \\
\text { produced } \\
(\mathrm{mg} / \mathrm{ml})\end{array}$ & $\begin{array}{c}\text { Growth } \\
(\text { OD }\end{array}$ \\
\hline $\begin{array}{c}\text { Increased resistance to } \\
\text { Triazolealanine }(>200 \mu \mathrm{g} / \mathrm{ml})\end{array}$ & 76 & TUMT-24 & 12.2 & 0.63 \\
$\begin{array}{c}\text { Thiazolealanine }(>1000 \mu \mathrm{g} / \mathrm{ml}) \\
\text { plus aminotriazole }(>1000 \mu \mathrm{g} / \mathrm{ml}) \\
\text { (Parent) }\end{array}$ & 10 & TUMA-1 & 10.1 & 0.39 \\
\hline
\end{tabular}

leucine auxotrophic derivative. ${ }^{2)}$ At the appropriate molasses-sucrose ratio, the level of the histidine production by these mutants became maximum. Therefore, the effect of molasses concentration on histidine production by TUMT-24 which gave the highest

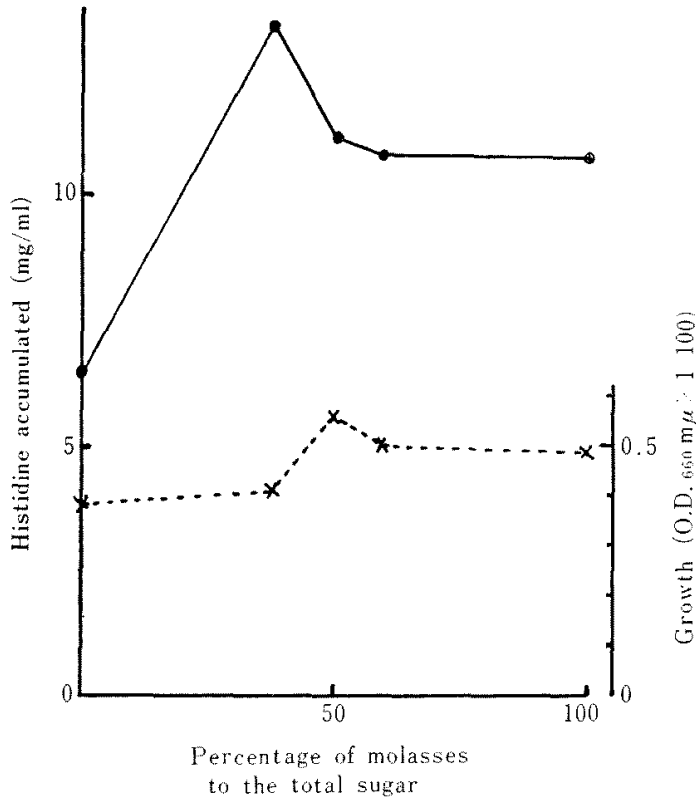

FIG. 3. Effect of Molasses-sucrose Ratio on Histidine Production by $C$. glatamicum TUMT-24.

a) Molasses/sucrose ratios in the fermentation media were adjusted by combining the following two media in different ratios. Medium $\mathrm{I}$ : Sucrose $15 \%, \mathrm{KH}_{2} \mathrm{PO}_{4}$ $0.2 \%, \mathrm{~K}_{2} \mathrm{HPO}_{4} \quad 0.1 \%, \mathrm{MgSO}_{4} \cdot 7 \mathrm{H}_{2} \mathrm{O} \quad 0.05 \%$, urea $0.2 \%\left(\mathrm{NH}_{4}\right)_{2} \mathrm{SO}_{4} 4 \%, \mathrm{FeSO}_{4} \cdot 7 \mathrm{H}_{2} \mathrm{O} 0.001 \%, \mathrm{MnSO}_{4}$. $4 \mathrm{H}_{2} \mathrm{O} \quad 0.001 \%$, meat extract $0.75 \%$, thiamine $\cdot \mathrm{HCl}$ $2500 \mu \mathrm{g} /$ liter, biotin $200 \mu \mathrm{g} /$ liter, $\mathrm{CaCO}_{3} 3 \%$. Medium II: Molasses $15 \%$ (as glucose concentration), $\mathrm{KH}_{2} \mathrm{PO}_{4} \quad 0.2 \%, \quad\left(\mathrm{NH}_{4}\right)_{2} \mathrm{SO}_{4} \quad 4 \%, \quad \mathrm{~K}_{2} \mathrm{HPO}_{4} \quad 0.1 \%$, $\mathrm{MgSO}_{4} \cdot 7 \mathrm{H}_{2} \mathrm{O} \quad 0.05 \%$, urea $0.2 \%$, meat extract $0.75 \%, \mathrm{CaCo}_{3} 3 \%$.

$\longrightarrow$, histidine; $\times--\times$, growth. yield of histidine in the preceding experiment was investigated. It was done with media containing $15 \%$ sugar comprising cane molasses and sucrose in different ratios. As can be seen in Fig. 3, the mutant produced 13.4 $\mathrm{mg} / \mathrm{ml}[8.9 \%(\mathrm{w} / \mathrm{w})$ of the initial sugar] of histidine under the condition where the molasses percentage is $37.5 \%$.

\section{Improvement by the addition of tryptophan analog-resistance}

The tryptophan inhibition of PRPP synthetase is known with crude extracts from $S$. typhimurium $^{9}$ and E. coli. ${ }^{11}$, Based on a similar assumption as that described for the derivation of purine analog-resistant mutants, we expected the high production of histidine by the mutant carring resistance to 5-methyltryptophan (5MT) which has been shown to be a regulator of the aromatic pathway of bacteria. ${ }^{32 \sim 34}$ )

Such mutants were derived from TUMT-24 which gave the highest yield of histidine in the preceding experiment, and cultured at first in a fermentation medium containing $15 \%$ (as glucose concentration) cane molasses. As can be seen in Tables VIII and IX (Exp. I), 5 out of 88 such mutants produced $12 \sim 12.6$ $\mathrm{mg} / \mathrm{ml}$ of histidine. These levels of histidine were comparable with or higher than those given by the parent strain TUMT-24 in the preceding experiment $(12.2 \mathrm{mg} / \mathrm{ml})$ and in this experiment $(9.6 \mathrm{mg} / \mathrm{ml}$, Exp. I in Table IX), respectively. Sixty-nine of these 5MTresistant mutants were cultured again in a medium containing $6 \%$ (as glucose concentra- 
TABle VIII. Distribution of 5-Methyltryptophan-Resistant Derivatives of C. glutamicum TUMT-24 with Respect to Histidine Productivity

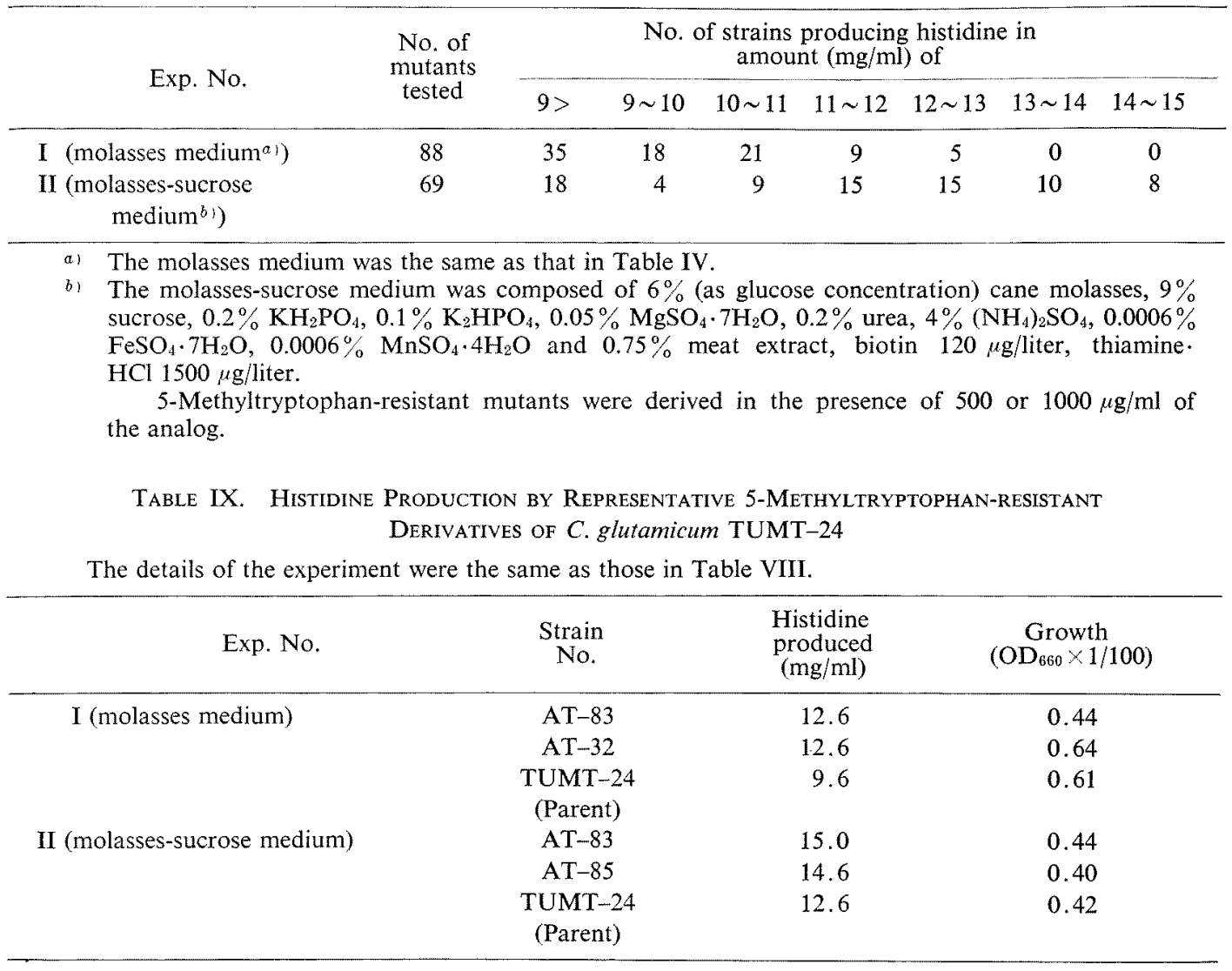

tion) cane molasses and $9 \%$ sucrose as carbon sources. The concentration $[40 \%(\mathrm{w} / \mathrm{w})$ of the total sugar] of molasses used was near the optimal one $(37.5 \%)$ for the histidine production by the parent strain TUMT-24. Eight of them produced $14 \sim 15 \mathrm{mg} / \mathrm{ml}$ of histidine (Exp. II in Table VIII), the values which were distinctly higher than those given by the parent strain in the preceding experiment $(13.4 \mathrm{mg} / \mathrm{ml}$, Fig. 3) and in this experiment $(12.6 \mathrm{mg} / \mathrm{ml}$, Exp. II in Table IX). The highest yield was given by AT-83 also under this condition, and the level of histidine produced by this mutant reached $15 \mathrm{mg} / \mathrm{ml}$ or $10 \%(\mathrm{w} / \mathrm{w})$ of the initial sugar.

\section{DISCUSSION}

The histidine productivity of a TRA-resistant histidine producer, C. glutamicum KY-10260 could be improved in a stepwise manner by the successive additions of such resistance markers as purine analog-resistance, pyrimidine analog-resistance, high resistance to histidine-analog and tryptophan analog-resistance to the mutant. The genealogy of AT-83, a finally selected mutant strain, and of the mutants which were employed as parent strain at each step of improvement is shown in Fig. 4, together with their histidine productivity. The improvement of the histidine productivity in each step was rather minor, but as a total a finally selected mutant strain, AT-83 produced approximately twice as much histidine as the original histidine producer KY-10260. Amongst the steps, the addition of 4TU-resistance resulted most significant increase in the histidine productivity. The distribution pattern of 4TU-resistant mutants with respect to histidine productivity (Table V) also supports 


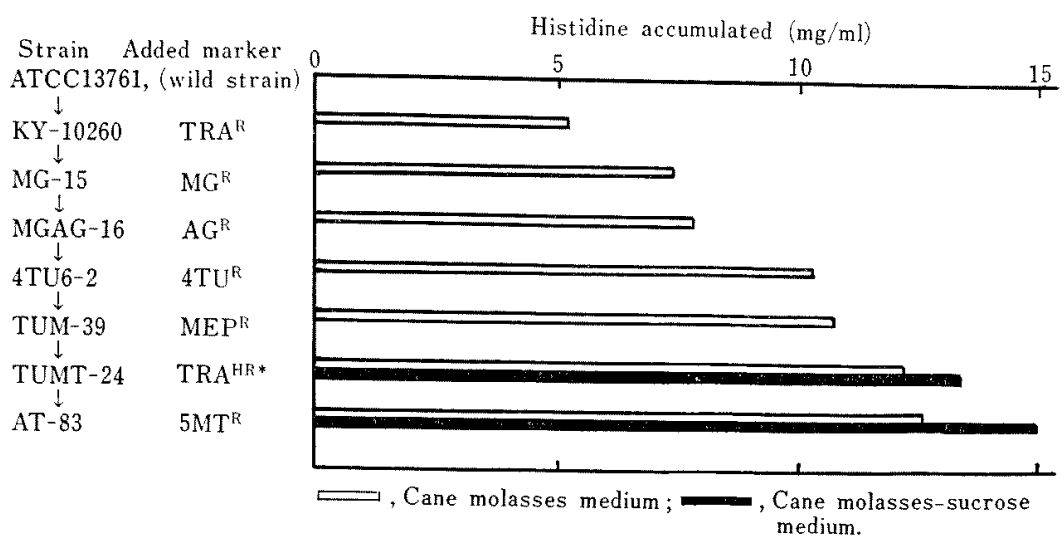

FIG. 4. Increase in Histidine Productivity by the Successive Additions of Purine, Pyrimidine, Histidine and Tryptophan Analog-resistance to C. glutamicum KY-10260.

* High resistance to TRA.

the significance of 4TU-resistance marker.

The rational of the improvements were based on the speculation that the regulatory mechanism on histidine biosynthesis and related biosynthesis known in some other microorganisms $^{2 \sim\{, 35,36)}$ would be applicable to Corynebacterium glutamicum. These are supplying of increased amount of PRPP and adenine nucleotide for histidine biosynthesis by releasing of the feed back regulation on their biosynthesis in the regulatory mutant obtainable as an end product-analog resistant. The improvement by increasing the resistance to TRA could be explained in terms of a further release of end product regulation in histidine pathway in consequence of the additional mutation at the regulatory site ${ }^{4)}$ other than the original one in KY-10260.

FA-resistant mutants derived from both histidine-producing mutants and a wild-type strain (ATCC 13761 ${ }^{30}$ ) of $C$. glutamicum accumulated a large amount of adenine in the culture medium. This is explained in terms of the lack of feed back regulation on the biosynthesis of adenine nucleotides, overproduction and decomposition of the nucleotides and excretion in the form of adenine base.

Acknowledgement. The authers are thankful to Mr. M. Teranishi for the synthesis of 2-fluoroadenine.

\section{REFERENCES}

1) K. Araki and K. Nakayama, Agr. Biol. Chem., 35, 2081 (1971).

2) K. Araki and K. Nakayama, ibid., 38, 189 (1974).

3) B. Magasanik, "The Bacteria," Vol. III, ed. by I. C. Gunsalus and R. Y. Stainer, Academic Press, New York, 1962, p. 295.

4) M. Brenner and B. N. Ames, "Metabolic Pathway," Vol. V, ed. by H.J. Vogel, Academic Press, New York and London, 1971, p. 349.

5) J. S. Gots, ibid., p. 225.

6) E. R. Stadtman, Adv. Enzymol., 28, 41 (1966).

7) H.S. Moyed and B. Magasanik, J. Biol. Chem., 235, 149 (1960).

8) B. N. Ames, R. G. Martin and B. J. Garry, ibid., 236, 2019 (1961).

9) R. L. Switzer, Federation Proc., 26, 560 (1967).

10) R. L. Switzer and D. C. Sogin, J. Biol. Chem., 248, 1063 (1973).

11) D. E. Atkinson and L. Fall, ibid., 242, 3241 (1967).

12) L. Klungsфyer, J. H. Hagemen, L. Fall and D. E. Atkinson, Biochemistry, 7, 4035 (1968).

13) M. N. White, J. Olszowy and R. L. Switzer, J. Bacteriol., 108, 122 (1971).

14) J. Olszowy and R. L. Switzer, ibid., 110, 450 (1972).

15) D. P. Nierlich and B. Magasanik, J. Biol. Chem., 240, 358 (1965).

16) I. Shiio and K. Ishii, J. Biochem., 66, 175 (1969).

17) J. B. Wyngaarden and R. A. Greenland, J. Biol. Chem., 238, 1054 (1963).

18) K. Ishii and I. Shiio, J. Biochem., 68, 171 (1970).

19) A. P. Levin and B. Magasanik, J. Biol. Chem., 236, 184( 1961).

20) D. P. Nierlich and B. Magasanik, Biochim. Biophys. Acta, 230, 349 (1971).

21) K. Ishii and I. Shiio, Agr. Biol. Chem., 37, 287 
(1973).

22) H. Nishikawa, H. Momose and I. Shiio, $J$. Biochem., 62, 92 (1967).

23) H. Momose, J. Gen. Appl. Microbiol., 13, 39 (1967).

24) J. A. Montgomery and K. Hewson, J. Amer. Chem. Soc., 82, 463 (1960).

25) F. Rottman and A. J. Guarino, Biochim. Biophys. Acta, 89, 465 (1964).

26) P. Roy-Burman, "Analogs of Nucleic Acid Components," Springer-Valag Berlin, Heiderberg, New York, 1970, p. 9.

27) M. E. Bails, "Antagonists and Nucleic Acids," North-Holland Publishing Co., Amsterdam, 1968.

28) Z. Sato, K. Nakayama, H. Tanaka and S. Kinoshita, Agr. Biol. Chem., 29, 412 (1965).
29) L. Lee Bennett, Jr. and D. Switzer, Biochem. Pharmacol, 13, 1331 (1964).

30) S. Shimojo, K. Araki and K. Nakayama, Nippon Nogeikagaku Kaishi (Tokyo), 48, 63 (1974).

31) G. A. Odonovan and J. Neuhard, Bacteriol. Rev., 34, 278 (1970).

32) J. C. Kuhn, M. J. Pabst and R. L. Somerville, J. Bacteriol., 112, 93 (1973).

33) J. Monod and G. Cohen-Bazire, Compt. Rend., 236, 530 (1953).

34) H. S. Moyed, J. Biol. Chem., 235, 1008 (1960).

35) M. E. Burke and P. A. Pattee, Can. J. Microbiol., 18, 569 (1972).

36) M. P. Stulberg, K. R. Isham and A. Stevens, Biochim. Biophys. Acta, 186, 297 (1969).

37) T. Nara, T. Komuro, M. Misawa and S. Kinoshita, Agr. Biol. Chem., 33, 739 (1969). 